\title{
Comparative effects of idazoxan, efaroxan, and BU 224 on insulin secretion in the rabbit: Not only interaction with pancreatic imidazoline $I_{2}$ binding sites
}

\author{
María José García-Barrado ${ }^{1}$, María Francisca Pastor ${ }^{1}$, María Carmen Iglesias-Osma ${ }^{1}$, \\ Christian Carpéné ${ }^{2}$, and Julio Moratinos ${ }^{1}$

\begin{abstract}
${ }^{1}$ Departamento de Fisiología y Farmacología, Facultad de Medicina, Universidad de Salamanca, Salamanca, Spain; $\underline{\text { barrado@usal.es }}$ ${ }^{2}$ INSERM, U586 (Institut National de la Santé et de la Recherche Médicale), Unité de Recherches sur les Obésités, Université Paul Sabatier, Institut Louis Bugnard IFR31, Toulouse, France
\end{abstract}

Received 6 November 2009; revised 1 December 2009; accepted 22 December 2009.

\begin{abstract}
The nature of the binding site(s) involved in the insulin secretory activity of imidazoline compounds remains unclear. An imidazoline $I_{2}$ binding site $\left(I_{2} B S\right)$ has been neglected since the classic $I_{2}$ ligand, idazoxan, does not release insulin. Using the rabbit as an appropriate model for the study of this type of binding sites, we have tried to re-evaluate the effects of idazoxan, the selective $I_{2}$ compound BU 224, and efaroxan on insulin secretion. Mimicking efaroxan, idazoxan and BU 224 potentiated insulin release from perifused islets in the presence of $8 \mathrm{mM}$ glucose. In static incubation, insulin secretion induced by idazoxan and BU 224 exhibited both dose and glucose dependencies. ATP-sensitive $\mathrm{K}^{+}$ ( $\left.K_{\text {ATP }}\right)$ channel blockade, though at a different site from the SUR1 receptor, with subsequent $\mathrm{Ca}^{2+}$ entry, mediates the insulin releasing effect of the three ligands. However, additional MAO independent intracellular steps in stimulussecretion coupling linked to PKA and PKC activation are only involved in the effect of $B U$ 224. Therefore, both an $\mathrm{I}_{2}$ related binding site at the channel level shared by the three ligands and a putative $\mathrm{I}_{3}$-intracellularly located binding site stimulated by BU 224 would be mediating insulin release by these compounds. In vivo experiments reassess the abilities of idazoxan and BU 224 to enhance glucose-induced insulin secretion and to elicit a modest blood glucose lowering response.
\end{abstract}

Keywords: BU 224; Efaroxan; Idazoxan; Imidazoline Ligands; Insulin Secretion; IVGTT (Intravenous Glucose Tolerance Test); $\mathrm{K}_{\text {ATP }}$ Channel; PK Activity; Rabbit
Pancreatic Islets

\section{INTRODUCTION}

A number of imidazoline containing compounds have been previously shown to induce insulin release from the perifused pancreas or isolated islets $[1,2]$ and to improve glucose tolerance in rats [3-5] and mice [6].

In accordance with the mechanisms of their insulinotropic effect, two groups of imidazoline compounds can be considered: classical imidazolines, i.e., imidazoline derivatives possessing both ATP-sensitive $\mathrm{K}^{+}\left(\mathrm{K}_{\mathrm{ATP}}\right)$ channel activity and a direct effect on exocytosis, like RX871024 [7], and a new generation of compounds without effect on $\mathrm{K}_{\mathrm{ATP}}$ channels though possessing a pure glucose-dependent insulinotropic effect like BL11282 [8]. The $\mathrm{K}_{\mathrm{ATP}}$ channel consists of two subunits: a sulphonylurea receptor (SUR1) and a Kir6.2 subunit. Classical imidazoline drugs bind to the transmembrane protein Kir6.2 [9] considered to be the pore-forming subunit of the channel whereas sulphonylureas bind to the SUR1 receptor. It is also established that the binding site for imidazolines and the sulphonylurea receptor are not identical since the first drugs do not displace binding from the SUR sites [10]. Additional sites located at more distal stages of the stimulus-secretion coupling pathway, mediating activation of protein kinase A (PKA) and protein kinase $\mathrm{C}(\mathrm{PKC})$ have also been reported $[8,11,12]$.

However, when trying to analyze the nature of the binding sites or receptors involved in their insulin secretory response a number of difficulties have emerged. An $\mathrm{I}_{2}$ imidazoline binding site $\left(\mathrm{I}_{2}\right.$-site) has been discarded since the classic $I_{2}$ ligand idazoxan exhibited a mild concentration independent increase in insulin release [13], failed to evoke any effect [14] or even blocked the response induced by efaroxan (an $\alpha_{2}$-adrenoceptor antagonist) with an imidazoline structure [15]. Similarly, the monoamine oxidase A (MAO-A) inhibitor clorgyline did 
not modify the insulin secretory response induced by the imidazoline compound RX871024 [16]. Radioligand binding studies performed in membranes from RINm5F and MIN6 cells, in the presence of [3H]-RX821002 (methoxy-idazoxan an imidazoline $\alpha_{2}$-adrenoceptor antagonist) showed a low affinity non-adrenergic binding site which could be displaced by efaroxan but not by idazoxan $[18,19]$. Therefore, evidence for a novel putative $I_{3}$ binding site involved in the insulin secretory response is being accepted. Efaroxan is tentatively considered an $\mathrm{I}_{3}$ ligand and 2-(2-ethyl-2,3-dihydro-benzofuran-2-yl)-imidazole (KU 14R), a close structural efaroxan analogue able to block its effect, an $\mathrm{I}_{3}$ antagonist $[18,20]$.

However, some recent data have yielded intriguing results: even high doses of efaroxan did not increase circulating insulin in mouse [21] and the selective $\mathrm{I}_{2}$ ligand: 2-(2-benzofuranyl)-2-imidazoline (2-BFI) releases insulin from isolated rat islets [10]. Considering the heterogeneity of imidazoline binding sites [22] and that the putative $\mathrm{I}_{3}$ binding site encompasses a nebulous group of loci, we have tried to re-evaluate the effect of imidazoline ligands on insulin release in rabbits. The rabbit was chosen as a suitable model in view of the paucity of this type of data for an animal species otherwise very rich in $\mathrm{I}_{2}$-binding sites [17,23,24]. 2-(4,5-dihydroimidazol-2-yl)quinoline (BU 224), considered a selective $\mathrm{I}_{2}$ ligand [25-27], idazoxan (a typical $\alpha_{2}$-adrenoceptor antagonist and $I_{2}$ ligand), methoxy-idazoxan (an $\alpha_{2}$-adrenoceptor antagonist) and efaroxan ( $\mathrm{I}_{3}$ putative ligand) were employed in both in vitro and in vivo experiments to delineate insulin secretion and glycaemic control.

\section{MATERIALS AND METHODS}

\subsection{Chemicals and Solutions}

Forskolin, diazoxide, tolbutamide, methoxy-idazoxan, nimodipine, yohimbine, 3-isobutyl-1-methylxanthine (IB MX), chelerythrine and pargyline were provided by SigmaAldrich (Spain); idazoxan was obtained from RekiltColman Pharmaceutical Company (Germany); brimonidine (UK 14,304) came from Pfizer (UK); 2-(4,5-dihydroimidazol-2-yl)-quinoline (BU 224 hydrochloride), efaroxan hydrochloride, and 2-(2-ethyl-2,3-dihydro-benzofuran-2-yl) -imidazole (KU 14R) were obtained from Tocris (Bristol, UK), calphostin and Rp-Adenosine-3',5'-cyclic monophosphothioate triethylamine (Rp-cAMPS) were from Bionova (Spain). Forskolin and chelerythrine were prepared in DMSO, and final concentrations of DMSO were $0.1 \%$ or less in each case.

\subsection{Animals}

The experiments were performed using male New Zealand white rabbits aged 7-12 months (body weight between $2.5-3.5 \mathrm{~kg}$ ). The animals were maintained in a $12 \mathrm{~h}$ light-dark cycle and were provided with free access to food and water. The study was conducted in accordance with the European Communities Council Directives for experimental animal care.

\subsection{In Vitro Experiments}

\subsubsection{Islet Isolation and Incubation}

The rabbits were sacrificed after the induction of general anaesthesia with $30 \mathrm{mg} \mathrm{kg}^{-1}$ i.v. of sodium pentobarbital (Abbott, Spain). The pancreas was removed and distended with bicarbonate-buffered physiological salt solution. The islets were isolated by collagenase (Inmunogenetic, Spain) and hand-picked using a glass loop pipette under a stereo microscope. They were free of visible exocrine contamination. The medium used for islet isolation was a bicarbonate-buffered solution containing $120 \mathrm{mM} \mathrm{NaCl}$, $4.8 \mathrm{mM} \mathrm{KCl}, 2.5 \mathrm{mM} \mathrm{CaCl}_{2}, 1.2 \mathrm{mM} \mathrm{MgCl}, 5 \mathrm{mM}$ HEPES and $24 \mathrm{mM} \mathrm{NaHCO}_{3}$. It was gassed with $\mathrm{O}_{2}-\mathrm{CO}_{2}$ (94: 6) to maintain a $\mathrm{pH}$ of 7.4 and was supplemented with $1 \mathrm{mg} \mathrm{ml}^{-1} \mathrm{BSA}$ and $10 \mathrm{mM}$ glucose. When the concentration of $\mathrm{KCl}$ was increased to $30 \mathrm{mM}$, that of $\mathrm{NaCl}$ was decreased accordingly. The concentration of glucose was adjusted and test substances were added as required.

\subsubsection{Measurements of Insulin Secretion}

After isolation, in the first type of experiments, the islets were pre-incubated for $60 \mathrm{~min}$ in a medium containing 15 $\mathrm{mM}$ glucose before being distributed into batches of three. Each batch of islets was then incubated for $60 \mathrm{~min}$ in $1 \mathrm{ml}$ at $37^{\circ} \mathrm{C}$ of medium containing $8 \mathrm{mM}$ glucose and test substances, Pargyline was added to the preincubation medium $40 \mathrm{~min}$ before incubation. A portion of the medium was withdrawn at the end of the incubation and its insulin content was measured by a double antibody-RIA (insulin CT, Schering, Spain).

In the other type of experiment, the isolated islets were divided in equal batches of 45-50 and placed in a parallel perifusion chamber at $37^{\circ} \mathrm{C}$ and perifused for $30 \mathrm{~min}$ before the start of the experiment at a flow rate of $1.1 \mathrm{ml}$ $\mathrm{min}^{-1}$. After a $30 \mathrm{~min}$ stabilisation period they were perifused with $8 \mathrm{mM}$ glucose and the appropriate compounds as indicated in the figure legends. Effluent fractions collected at 2 min intervals were chilled until their insulin content was measured by RIA.

\subsubsection{In Vivo Experiments}

The experimental design carried out on conscious $24 \mathrm{~h}$ fasted animals has been fully described in other publications [28, 29]. Arterial blood was sampled by means of an indwelling cannula placed in the central artery of one ear. Two control samples, separated by an interval of $30 \mathrm{~min}$, were taken before drug infusion started. Drug solutions were infused at a constant rate $\left(0.15 \mathrm{ml} \mathrm{min}^{-1}\right)$ for $30 \mathrm{~min}$ through an indwelling cannula, which was kept functional by a slow constant infusion of physiological saline $(0.07$

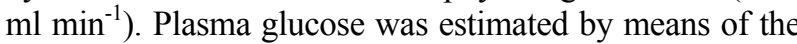
glucose oxidase procedure using a kit from Atom (Madrid, Spain). Insulin was determined by using a radioimmunoassay kit (Schering, Spain), with human insulin as standard. 


\subsubsection{Statistics}

Statistical significance was determined using the Student's $t$ test for unpaired data or analysis of variance in conjunction with the Newman-Keuls test for unpaired data. A $P$ value $\leq 0.05$ was taken as significant. Values presented in the Figures and Results represent means \pm s.e.m. of at least 6 observations.

\section{RESULTS}

\subsection{Effects of Imidazoline Ligands on Insulin Release in Perifused Islets}

The time course of the effects of imidazoline ligands on insulin release was studied in perifused islets. Idazoxan, BU 224 and efaroxan, each at the equivalent dose of 100 $\mu \mathrm{M}$, potentiated the insulin secretory response induced by $8 \mathrm{mM}$ glucose (Figure 1).

\subsection{Effects of Imidazoline Ligands and $\alpha_{2}$-Adrenoceptor Antagonists on Insulin Release from Isolated Islets. Glucose Dependency}

When islets were incubated in $8 \mathrm{mM}$ glucose, methoxy-idazoxan in the range $10 \mu \mathrm{M}$ to $1 \mathrm{mM}$ was unable to evoke insulin release. However, idazoxan at the same concentration range induced a clear dose dependent increase in insulin secretion (Figure 2A). Similar results were found when islets were incubated in the presence of efaroxan and BU 224 (1-100 $\mu \mathrm{M}$, Figure 2B). As a marked significant increase in insulin release was observed at $100 \mu \mathrm{M}$ of either ligand, this particular imidazoline drug concentration was used for further studies.

Interestingly, the inhibitory effect on glucose induced insulin release mediated by $1 \mu \mathrm{M}$ of the selective $\alpha_{2}$-adrenoceptor agonist brimonidine (BRM, 55\% reduction) was
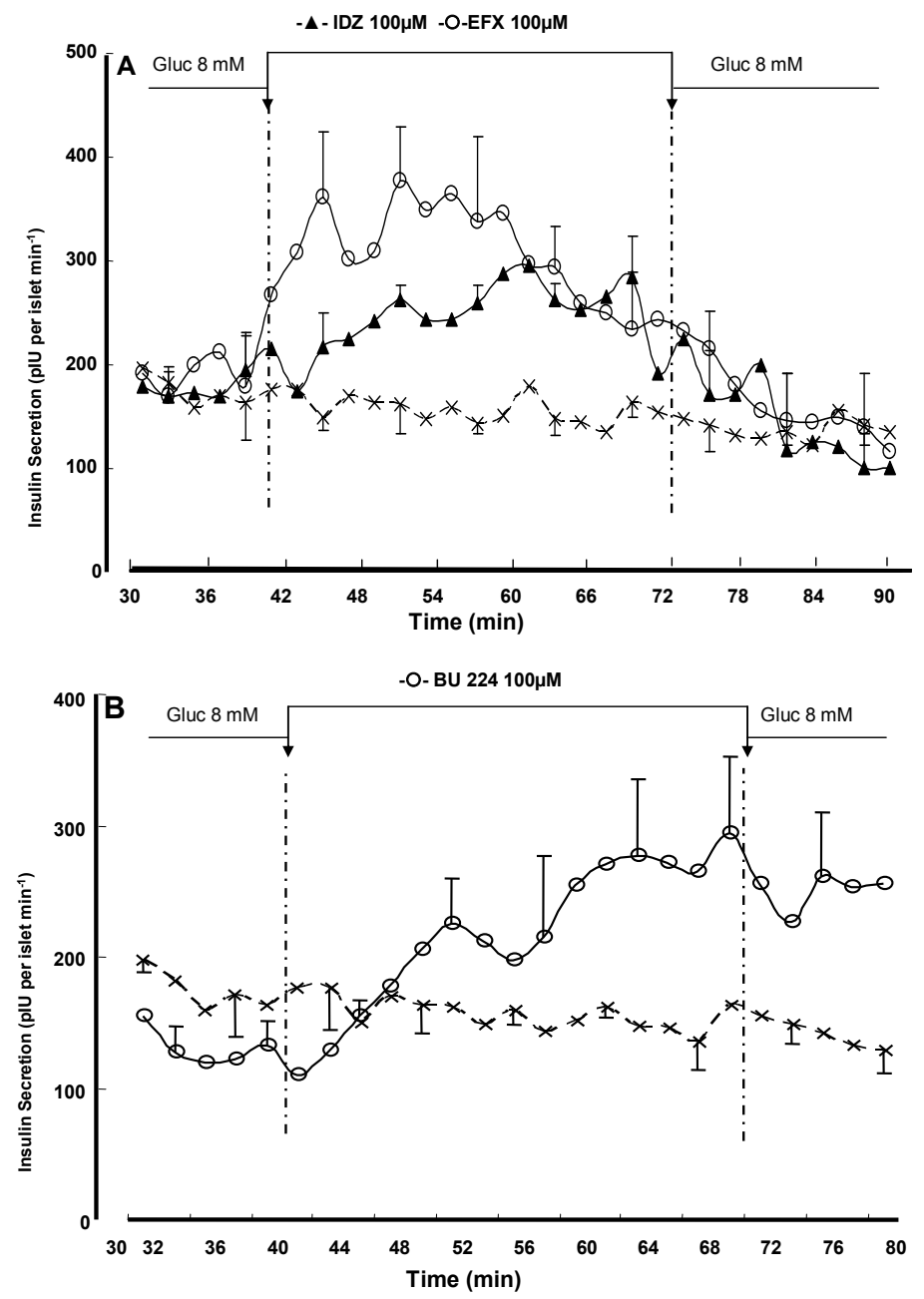

Figure 1. Effects of imidazolines on insulin release from rabbit perifused islets. Groups of 40 islets were perifused throughout the experiment with a medium containing $8 \mathrm{mM}$ glucose (-X-). Test substances were introduced between 40 and 70min: (A) $100 \mu \mathrm{M}$ idazoxan (- $\mathbf{\Delta - )}$ or $100 \mu \mathrm{M}$ efaroxan (-O-); (B) 100 $\mu \mathrm{M}$ BU224 (-O-). Values are mean \pm s.e.m. for four to six experiments. 

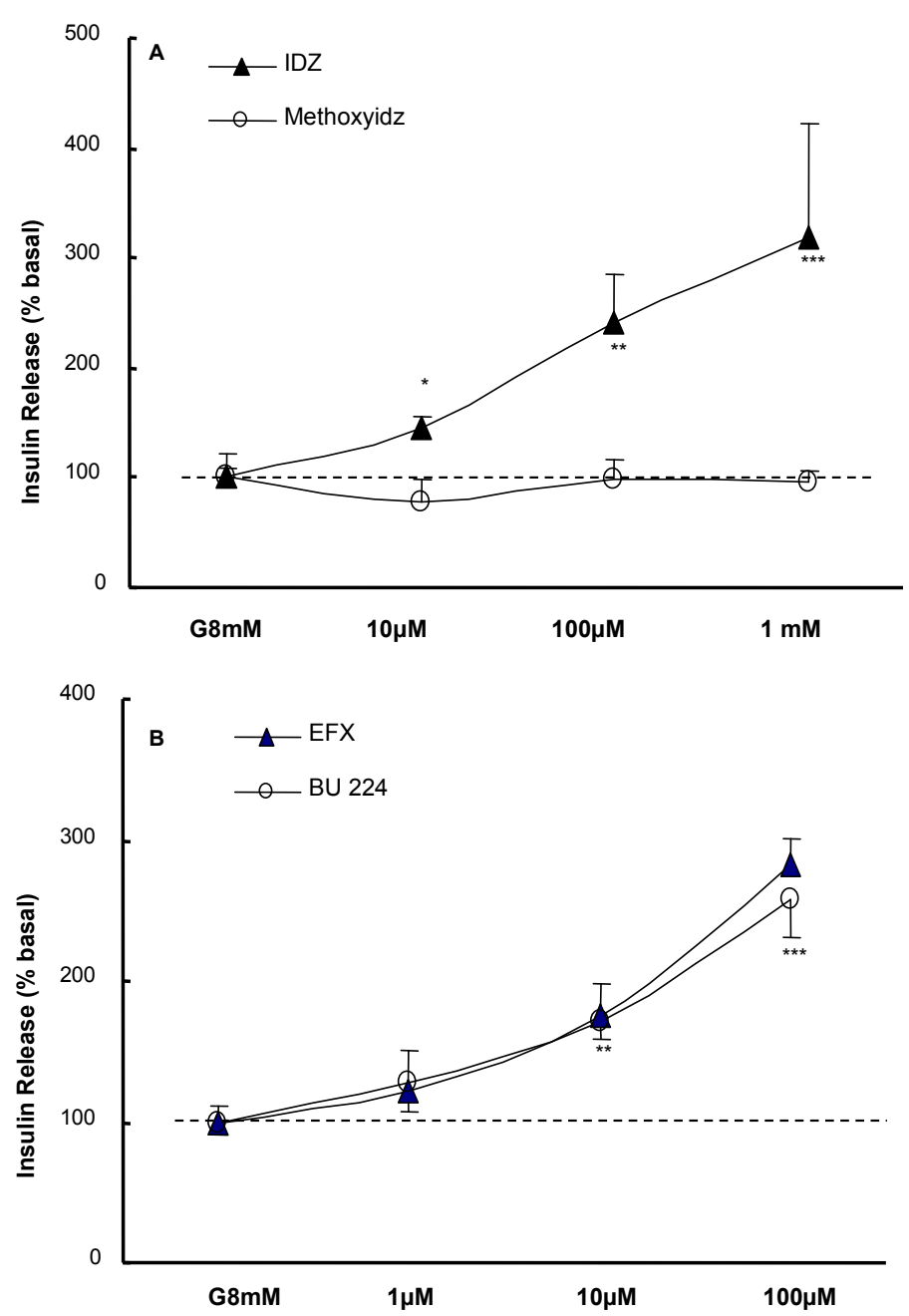

Figure 2. Dose-dependent effects of idazoxan (IDZ), methoxy-idazoxan (Methoxyidz) in (A); efaroxan (EFX) and BU 224 in (B) on insulin release from rabbit islets incubated in the presence of $8 \mathrm{mM}$ glucose in static condition. Each value represents the mean \pm s.e.m. from at least 10 observations. $* P<0.05$, $* * P<0.01$, and $* * * P<0.001$ indicate statistically significant percentage increase relative to $8 \mathrm{mM}$ glucose. Basal insulin release at this particular nutrient concen tration was: $9.65 \pm 1.1 \mu \mathrm{IU} \mathrm{ml}^{-1}$ islet $^{-1} \mathrm{~h}^{-1}$.

completely reversed by $1 \mu \mathrm{M}$ idazoxan, thus demonstrating the dual nature ( $\mathrm{I}_{2}$ ligand and $\alpha_{2}$-adrenoceptor antagonist) of this compound. However, the $\alpha_{2}$-adrenoceptor agonist clearly blunted the response to BU 224 (Figure 3). As expected, neither yohimbine nor methoxy-idazoxan affected the response to glucose, though the latter antagonist blocked the inhibitory response to brimonidine.

It is known that efaroxan is able to potentiate glucose induced insulin release over the range of 4-10 $\mathrm{mM}$ glucose [30]. Therefore, the effects of idazoxan and BU 224 $(100 \mu \mathrm{M})$ were also investigated at different glucose concentrations. Both ligands, mimicking efaroxan, enhanced insulin secretion from 3-15 mM glucose (Figure 4). In the absence of nutrient these imidazolines failed to release insulin and they did not modify the maximal secretory response to $30 \mathrm{mM}$ glucose.

\subsection{Interaction with $\mathrm{K}_{\mathrm{ATP}}$ Channels}

The effects of the three ligands on glucose induced insulin secretion were tested in the presence of $250 \mu \mathrm{M}$ diazoxide. As expected, the $\mathrm{K}_{\text {ATP }}$ channel opener inhibited the response to glucose (a $42.5 \%$ reduction) and completely suppressed the effect of idazoxan. However, both efaroxan and BU 224 significantly reversed the inhibitory effect mediated by the channel agonist (Figure 5A).

Since imidazoline compounds and sulphonylureas block the $\mathrm{K}_{\mathrm{ATP}}$ channel, though interacting with different and specific binding sites, the effect of the simultaneous addition of BU 224 plus tolbutamide on glucose mediated insulin secretion was also studied. When added alone BU 224 or $200 \mu \mathrm{M}$ of the sulphonylurea compound both drug induced significant increases in insulin release $(80 \%$ and 

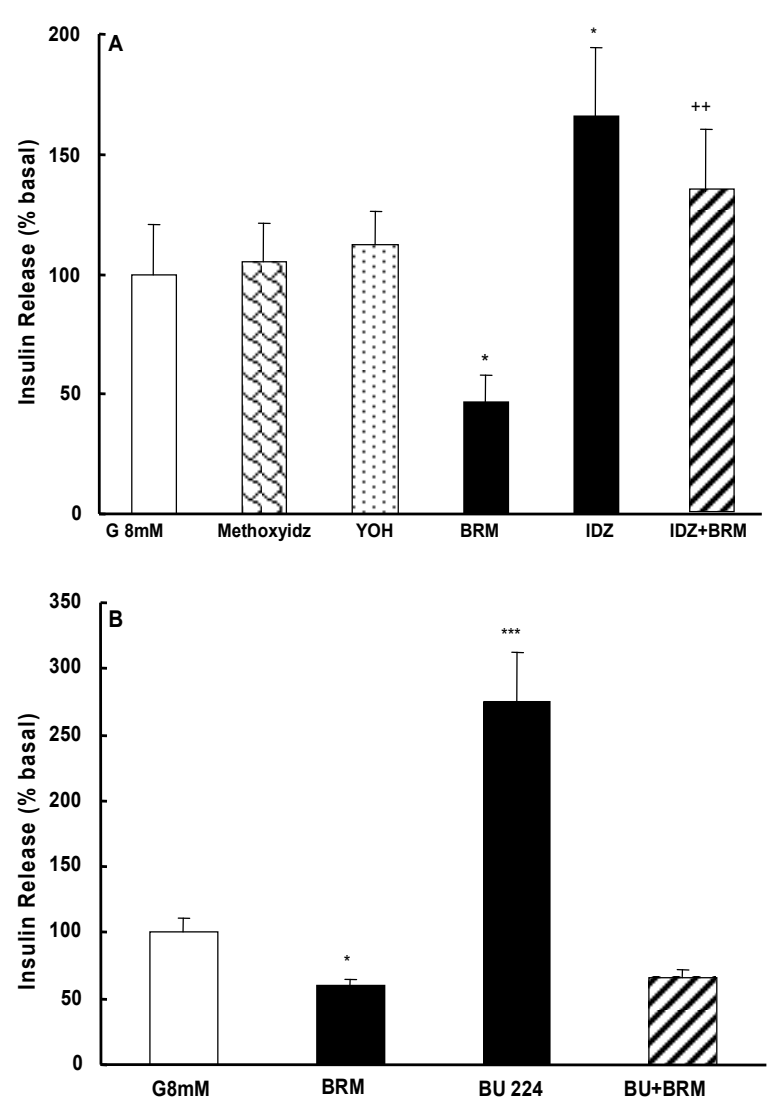

Figure 3. Inhibition of glucose induced insulin release by the $\alpha_{2}$-adrenoceptor agonist brimonidine (BRM, $1 \mu \mathrm{M}$ ) when added alone $(\boldsymbol{\square})$ or in the presence of $100 \mu \mathrm{M}$ of either idazoxan $(\boldsymbol{\square}, \mathrm{A})$ or BU $224(\square$, B). The effects of both imidazoline ligands $(100$ $\mu \mathrm{M})$, the $\alpha_{2}$-adrenoceptor antagonist yohimbine ( $\mathrm{YOH}, 5 \mu \mathrm{M}$ $\Xi)$, and methoxy-idazoxan (Methoxyidz, $5 \mu \mathrm{M}$ ) by themselves are also shown. $* P<0.05$ and $* * * P<0.001$ represent significant percentage decrease or increase relative to $8 \mathrm{mM}$ glucose. $++P<0.01$ when comparing to BRM alone. Basal insulin release from rabbit islets in static incubation was $12.32 \pm 1.4 \mu \mathrm{IU} \mathrm{ml}^{-1}$ islet $^{-1} \mathrm{~h}^{-1}$. Data are from at least 12 experiments.

and $51 \%$, respectively). When added together, the insulin secretory response was clearly enhanced $(\Delta=190 \%)$, thus the effect found with this drug association was significantly higher than the response induced by either drug alone (data not shown).

Interestingly in fresh isolated rabbit islets, idazoxan did not block the response to efaroxan. However neither synergism nor antagonism was found when two imidazoline ligands (either efaroxan-idazoxan, efaroxan-BU 224) were added together (Figure 5B).

\subsection{Role of $\mathrm{Ca}^{2+}$ on Insulin Release Induced by Imidazoline Ligands}

The calcium channel blocker nimodipine $(5 \mu \mathrm{M})$ attenuated the insulin secretory response to $8 \mathrm{mM}$ glucose (by $36.5 \%, P<0.05$ ) and significantly reduced the

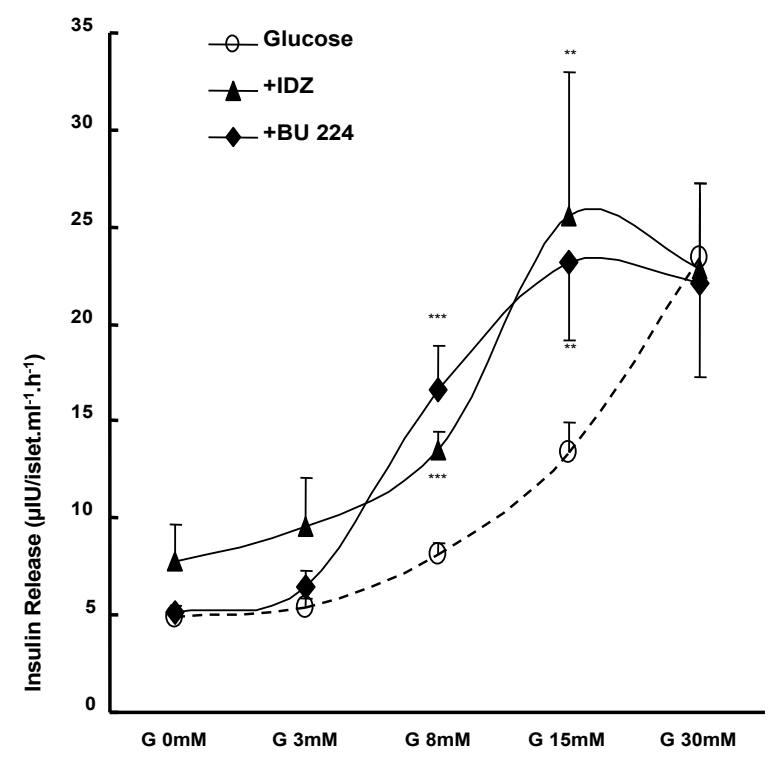

Figure 4. The effect of idazoxan or BU $224(100 \mu \mathrm{M}$, $\diamond$ each $)$ on insulin release in isolated rabbit pancreatic islets in the presence of different glucose $(\mathrm{G})$ concentrations. Results are mean \pm s.e.m. from at least 14 experiments. $* * P<0.01$ and $* * * P<0.001$, values significantly different relative to their corresponding glucose concentration.

stimulatory effect of BU 224. Interestingly, nimodipine abolished the response to idazoxan (inhibitory degree: $67.6 \%$, Figure 6A).

The effects of both ligands were also explored in a low calcium medium $\left(1 \mathrm{mM} \mathrm{Ca}^{2+}\right)$, but in the presence of a higher glucose concentration $(15 \mathrm{mM}) . \mathrm{Ca}^{2+} \mathrm{re}-$ duction significantly attenuated the responses to glucose and BU 224 (from $11.90 \pm 2.10$ to $5.35 \pm 0.35 \mu \mathrm{IU} \mathrm{ml}^{-1}$ and from $23.25 \pm 4.30$ to $12.45 \pm 0.65 \mu \mathrm{IU} \mathrm{ml}^{-1}$, respectively, $P<0.01$ ), though, interestingly, the per-centage increase in insulin secretion mediated by the ligand was of similar magnitude in both media (Figure 6A). Idazoxan elicited a tiny effect.

\subsection{Role of the $\mathrm{K}_{\mathrm{ATP}}$-Independent Pathway on Insulin Release Mediated by Imidazolines}

The experimental approach followed was as has been described [31]. The response to $8 \mathrm{mM}$ glucose was already enhanced when islets were incubated in a medium containing $30 \mathrm{mM}$ potassium and $250 \mu \mathrm{M}$ diazoxide ( $64.7 \%$ increase). BU 224 , but neither idazoxan or efaroxan, still induced a significant insulin secretory effect $(\Delta=80 \%, P<0.05$, Figure 6B).

\subsection{Intracellular Sites Involved in the Insulin Secretory Activity of Imidazolines}

Since true $\mathrm{I}_{2}$ ligands are reported to be linked to MAO enzymes, it was necessary to test the effect of a nonselective MAO inhibitor on insulin release in the presence of the three ligands. Pargyline $(10 \mu \mathrm{M})$ did not modify the 
response to either glucose or any of the ligands under investigation (Figure 9B).

When either BU 224 or efaroxan was assayed in the presence of forskolin $(10 \mu \mathrm{M})$, drug interaction led to an enhanced insulin secretory response (percentage increases with BU 224, forskolin and both together were: $135.5,149.7$ and 438.2, respectively; similarly, in the case of efaroxan, the results were: 100.9, 149.7, and 407.9). In the same way, the stimulatory response to BU 224 was potentiated by $100 \mu \mathrm{M}$ of the phosphodiesterase inhibitor 3-isobutyl-1-methylxanthine (IBMX, 312\%). Again, the increase derived from drug combination (association with either forskolin or IBMX) was significantly higher than the effect found with any drug alone (Figure 7, $\Delta$ to IBMX alone $=177.3 \pm 24.5 \%$ ).

Neither glucose nor efaroxan and idazoxan induced insulin release were affected by the presence of $\mathrm{Rp}$ -
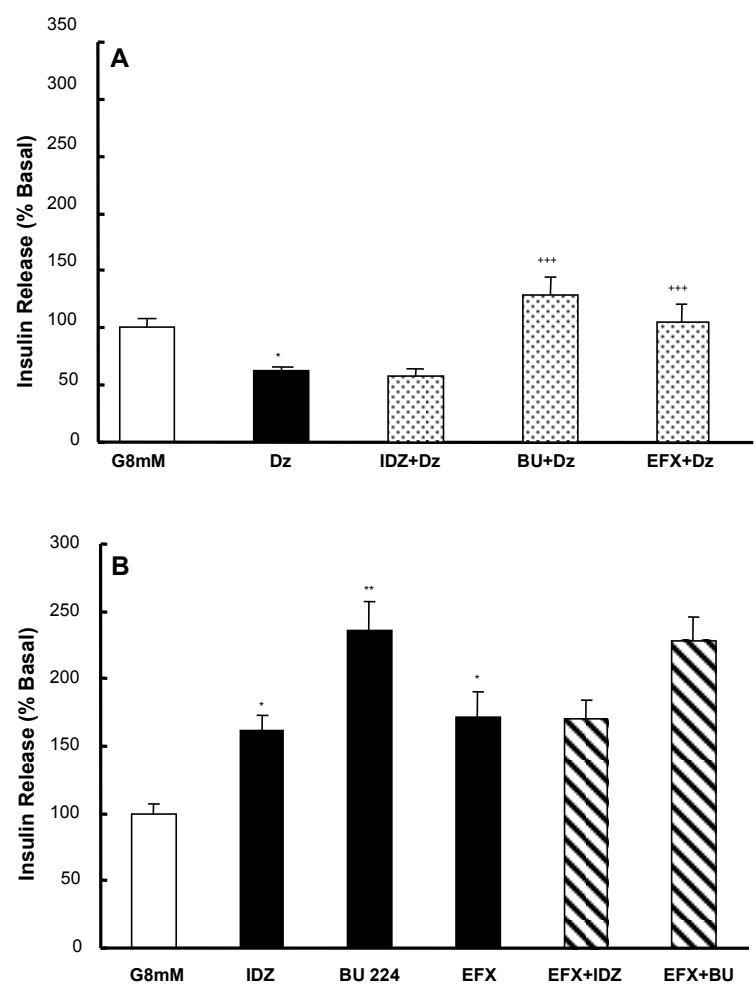

Figure 5. (A): Reversal of diazoxide induced inhibition of secretion by imidazoline ligands. $250 \mu \mathrm{M}$ of the channel opener were added to islets incubated in $8 \mathrm{mM}$ glucose in the absence (घ) or presence (B) of $100 \mu \mathrm{M}$ of the three different ligands: idazoxan, BU 224 and efaroxan. ${ }^{*} P<0.05$ statistically significant percentage reduction relative to glucose; $+++P<0.001$ when comparing to diazoxide. Basal insulin release was $6.7 \pm 0.8$ $\mu \mathrm{IU} \mathrm{ml} l^{-1}$ islet $^{-1} \mathrm{~h}^{-1}$. Each value represents the mean \pm s.e.m. from at least 12 experiments. (B): Insulin release from isolated islets in the presence of the different imidazoline ligands added either separately $(\mathbf{\square})$ or together $(\mathbf{\nabla})$ as shown. $100 \mu \mathrm{M}$ of each ligand was always applied. Basal insulin release in the presence of 8 $\mathrm{mM}$ glucose was: $7.45 \pm 0.55 \mu \mathrm{IU} \mathrm{ml}^{-1}$ islet $^{-1} \mathrm{~h}^{-1}$. Data represent the mean from at least 17 observations.
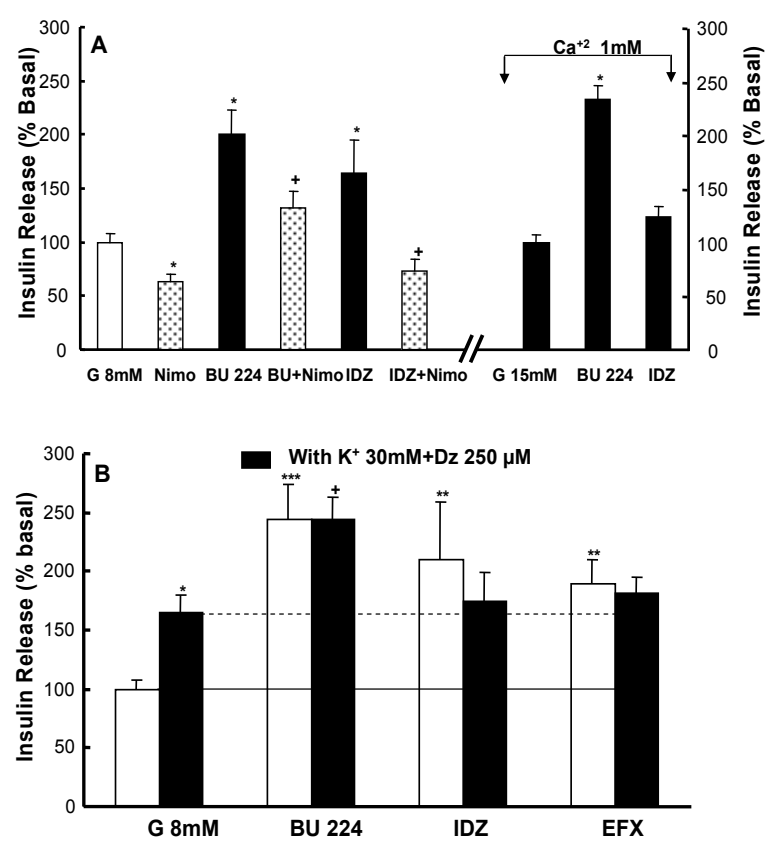

Figure 6. (A): Effects of BU 224 and idazoxan on insulin release in the absence ( $\square$ ) and presence ( $\mathrm{O}$ ) of $5 \mu \mathrm{M}$ nimodipine $* P<0.05$ represents statistically significant percentage inhibition relative to glucose; $+P<0.05$, percentage when comparing to either ligand. Basal insulin release was: $7.6 \pm 0.6 \mu \mathrm{IU} \mathrm{ml}^{-1}$ islet $^{-1}$ $\mathrm{h}^{-1}$. On the right: rabbit islets were incubated in a low calcium medium (1 mM) but with a higher glucose concentration (15 $\mathrm{mM})$. In these experimental conditions insulin release was $5.35 \pm 0.3 \mu \mathrm{IU} \mathrm{ml}^{-1}$ islet $^{-1} \mathrm{~h}^{-1}$. The effects of BU 224 and IDZ are shown. (B): The insulin secretory responses induced by BU 224, idazoxan and efaroxan in the presence of $30 \mathrm{mM} \mathrm{KCl}$ and 250 $\mu \mathrm{M}$ diazoxide ( $\square$ ). The effect found in normal medium ( $\square$ ) is also presented for comparison. $* P<0.05$, significant percentage increase relative to normal medium; $+P<0.05$, percentage increase when compare to insulin release from the medium enriched whit $\mathrm{KCl}$ and diazoxide. Basal insulin secretion in normal medium: 9.1 $\pm 0.9 \mu \mathrm{IU} \mathrm{ml} \mathrm{I}^{-1}$ islet ${ }^{-1} \mathrm{~h}^{-1}$. Data from these different experimental designs come from at least 14 observations.

Adenosine-3',5'-cyclic monophosphothioate triethylamine (Rp-cAMPS, $200 \mu \mathrm{M}$ ). This PKA inhibitor did attenuate the effect of BU 224, though a residual significant increase of $34 \%$ above basal levels was still observed with this ligand (Figure 8A). The PKC inhibitor chelerytrine $1 \mu \mathrm{M}$ [32] did not alter glucose induced insulin release though significantly blocked the response to BU 224 Figure 8B). However insulin secretion in the presence of idazoxan or efaroxan was not modified by chelerytrine. Similarly, calphostin $(1 \mu \mathrm{M})$, another Protein-Kinase C inhibitor, completely suppressed the effect of (BU 224 (from 21.3 \pm 2.9 to $11.9 \pm 1.7 \mu \mathrm{IU} \mathrm{ml} l^{-1}$ islet ${ }^{-1} \mathrm{~h}^{-1}$, insulin secretion in the presence of $8 \mathrm{mM}$ glucose being= 11.6 $\pm 1.4 \mu \mathrm{IU} \mathrm{ml} \mathrm{m}^{-1}$ islet ${ }^{-1} \mathrm{~h}^{-1}$ ), the response to efaroxan (22.2 \pm 4.7 and $22.0 \pm 4.4 \mu \mathrm{IU} \mathrm{ml} \mathrm{m}^{-1}$ islet $^{-1} \mathrm{~h}^{-1}$ remaining unaltered in the absence and presence of the inhibitor. Data are from at least 12 experiments). 


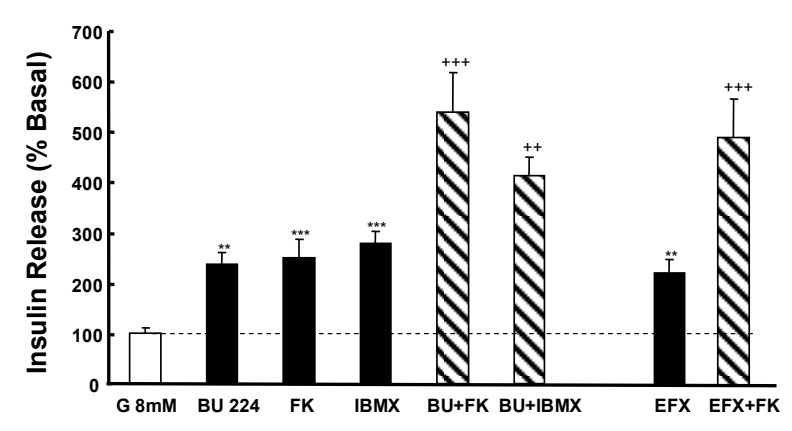

Figure 7. Stimulation of insulin release by BU 224 and efaroxan when added alone ( $\mathbf{m})$ or in the presence of either $10 \mu \mathrm{M}$ forskolin or $100 \mu \mathrm{M}$ 3-isobutyl-1-methylxanthine (IBMX, $\mathbf{\nabla}$ ). Rabbit islets were incubated in $8 \mathrm{mM}$ glucose throughout the experiment. $* * P<0.01$ and $* * * P<0.001$ represent significant percentage increase relative to glucose; $++P<0.01$ and $+++P<0.001$, synergistic percentage increase. Basal insulin release: $7.1 \pm 1.0$ $\mu \mathrm{IU} \mathrm{ml}{ }^{-1}$ islet $^{-1} \mathrm{~h}^{-1}$. Data are from at least 14 observations.
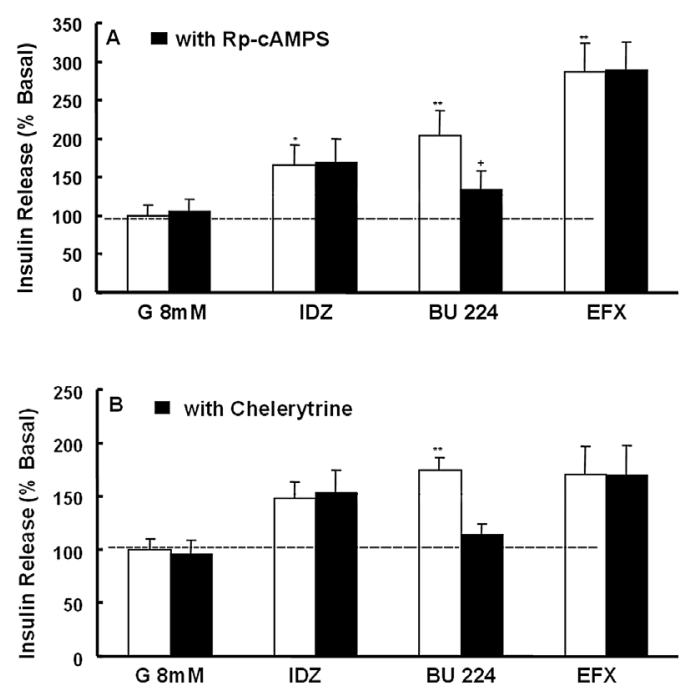

Figure 8. (A): Stimulatory effect on insulin secretion induced by idazoxan, BU 224 and efaroxan when added alone $(\square)(100 \mu \mathrm{M}$, of either ligand) or in the presence of $200 \mu \mathrm{M}$ of the selective PKA inhibitor Rp-cAMPS (घ). (B): The insulin secretory response of the three imidazoline ligands, alone ( $\square$ ) or in the presence of $1 \mu \mathrm{M}$ of the PKC inhibitor Chelerythrine ( $\mathbf{m})$. The effects of both inhibitors on glucose induced insulin release are also shown. $* P<0.05$ and $* * P<0.01$, significant percentage increase relative to glucose; $+P<0.05$ and $++P<0.01$ when comparing to ligand alone. Basal insulin release: (A) $12.9 \pm 1.3$ and (B) 11.9 $\pm 1.1 \mu \mathrm{IU} \mathrm{ml} l^{-1}$ islet $^{-1} \mathrm{~h}^{-1}$. Data are from at least 13 observations.

The compound 2-(2-ethyl-2,3-dihydro-benzofuran-2yl)-imidazole (KU 14R, $100 \mu \mathrm{M})$ did not alter glucose induced insulin release, but selectively reduced the effect of BU 224 (from a $124.5 \%$ to a $30.5 \%$ increase), therefore, responses to idazoxan and efaroxan remained unchanged. This reported antagonist also lowered forskolin induced insulin secretion (from a $329 \%$ to a $158 \%$ increase, $P<0.05)$, (Figure 9A).
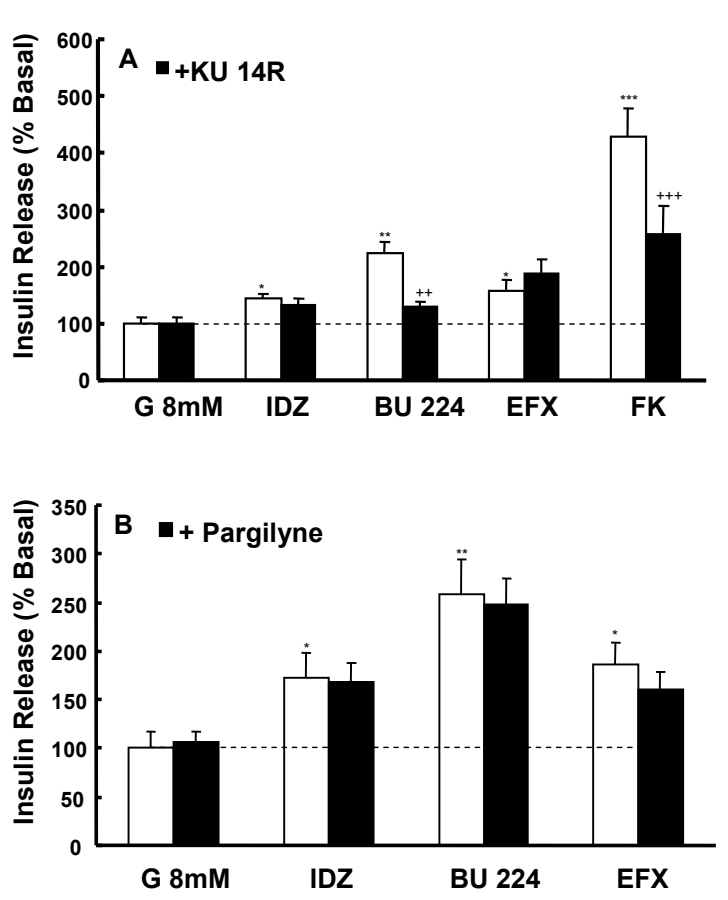

Figure 9. (A): The effect of the compound KU 14R $(100 \mu \mathrm{M})$ on insulin release induced by the three imidazoline ligands and $10 \mu \mathrm{M}$ forskolin. (B): The insulin secretory effect of three imidazoline ligands in the absence ( $\square$ ) and presence ( $\square$ ) of the dual MAO inhibitor pargyline $(10 \mu \mathrm{M})$. Basal insulin secretion when islets were bathed in $8 \mathrm{mM}$ glucose: (A) $7.8 \pm 0.8$ and (B) $5.6 \pm 0.5 \mu \mathrm{IU} \mathrm{ml}{ }^{-1}$ islet $^{-1} \mathrm{~h}^{-1} . * P<0.05$ and $* * P<0.01$, significant percentage increase relative to glucose. $+P<0.05$ and $+++P$ $<0.001$, when compared to secretagogue alone. Data were obtained from at least 17 observations.

\subsection{Effects in the Presence of Yohimbine, Idazoxan, BU 224 and Efaroxan on Intravenous Glucose Tolerance Test and Plasma Insulin Levels, Studies in Conscious Fasted Rabbits}

When infused alone at the equivalent dose of $10 \mu \mathrm{g} \mathrm{kg}^{-1}$ $\mathrm{min}^{-1}$, neither yohimbine [29], nor idazoxan modified basal values of either plasma glucose or circulating insulin (Figure 10). Interestingly, after the administration of BU 224 at the same dose, the ligand induced a progressive, persistent and significant increase in plasma insulin ( $\Delta$ at $\quad 45 \quad \min =184.40 \pm 42.95 \%, \quad n=5, \quad P<0.05, \quad v s$. $1.27 \pm 6.75 \%, n=7$ in saline treated animals, see Figure 11). The pre-infusion plasma glucose level was: $6.25 \pm 0.80 \mathrm{mM}, n=5$. These levels were not significantly modified after drug infusion.

Pre-treatment with yohimbine did not modify the responses to a glucose load $\left(10 \mathrm{mg} \mathrm{kg}^{-1} \mathrm{~min}^{-1}\right)$, (Figure 10). $\Delta$ in plasma glucose at $30 \mathrm{~min}$ in the absence and presence of yohimbine was, respectively, $3.87 \pm 0.3 \mathrm{mM}, n=8$, 

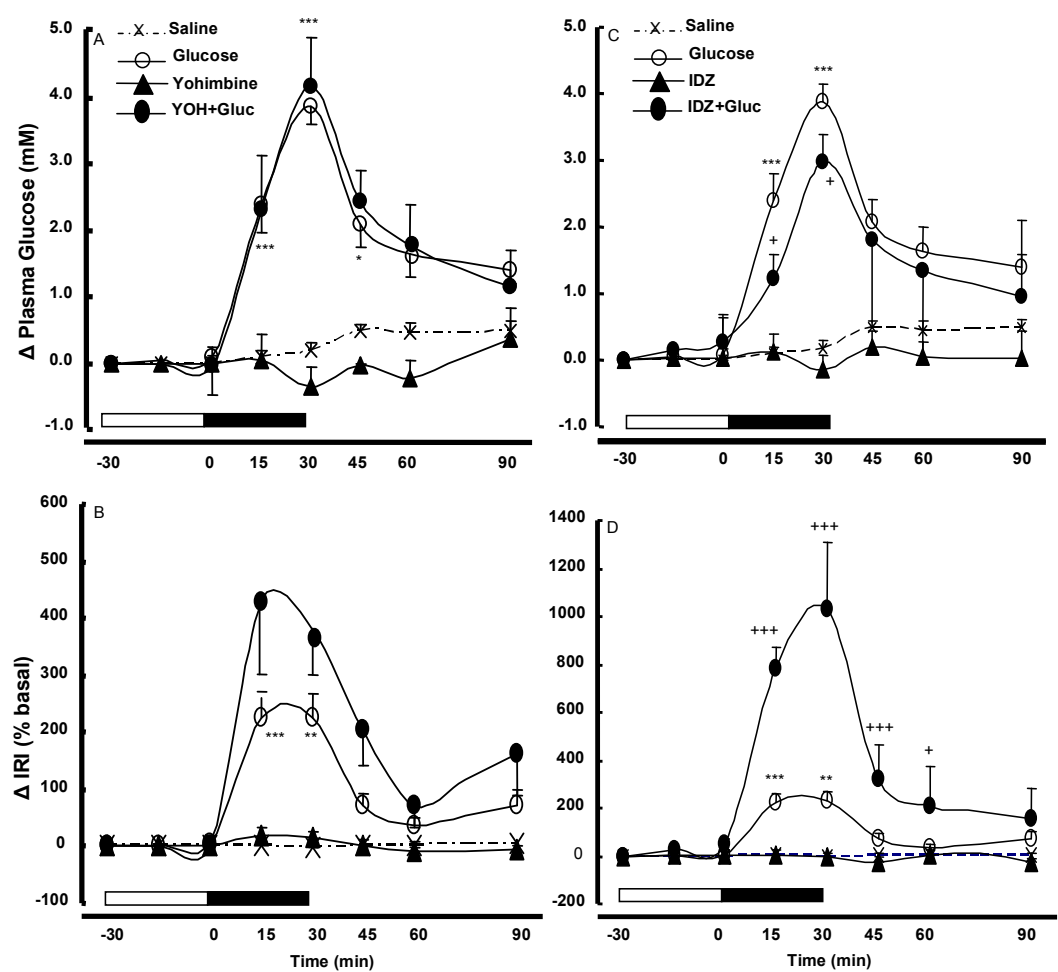

Figure 10. Effects of a glucose load $\left(10 \mathrm{mg} \mathrm{kg}^{-1} \mathrm{~min}^{-1}\right)$ on plasma glucose (A and C) and circulating insulin levels (B and D) in the absence (-O-) and presence of yohimbine (left) or idazoxan (right) (- -) in conscious fasted rabbits. The effects of saline (-X-), yohimbine and idazoxan $\left(-\mathbf{\Lambda}-, 10 \mu \mathrm{g} \mathrm{kg}^{-1} \mathrm{~min}^{-1}\right)$ by themselves on both parameters are also presented; saline or drugs were administered for 30min (white horizontal bar) alone or before a 30min i.v. glucose load (black bar). Ordinate scales, $\Delta \mathrm{mM}$ plasma glucose refers to the variations from control values. $\Delta$ IRI levels are expressed as percentage changes from the control level (control $=100 \%$ ). Each point of any given curve represents the mean \pm s.e.m. for at least 6 rabbits. Vertical lines indicate s.e.m. ${ }^{* *} P<0.01$ and $* * * P<0.001$, values significantly different between glucose and saline. $+P<0.05$ and $+++P<0.001$, values significantly different between glucose $v s$. glucose+idazoxan.

vs. $4.17 \pm 0.75 \mathrm{mM}, n=6$, N.S. $\Delta$ in immunoreactive insulin (IRI) plasma levels, also at $30 \mathrm{~min}$, in the absence and presence of the drug were: $226.55 \pm 40.55 \%, n=8$, vs. $380 \pm 102 \%, n=6$. No significant difference in the area under the insulin curve was found between glucose and yohimbine pre-treated animals $(98.5 \pm 27.93$ vs. $141.06 \pm$ $31.22 \mu \mathrm{IU} \mathrm{ml}^{-1} \mathrm{~h}^{-1}, n=6$ ).

However, in the presence of idazoxan $\left(10 \mu \mathrm{g} \mathrm{kg}^{-1}\right.$ $\left.\mathrm{min}^{-1}\right)$, glucose evoked a greater rise in IRI levels, (Figure 10) $(\Delta$ at $30 \mathrm{~min}=1032.90 \pm 278.60 \%, n=6, P<0.01$ when compared to glucose alone). A significant reduction in plasma glucose was also observed $(\Delta$ at 15 and $30 \mathrm{~min}$ in the presence of the drug being $1.22 \pm 0.38$ and $2.98 \pm 0.4$ $\mathrm{mM}, n=6, P<0.05)$.

When the glucose load was assayed in animals pre-treated with BU 224, this ligand induced both a reduction in plasma glucose ( $\Delta$ at $30 \mathrm{~min}$ in the absence and presence of the drug being: $3.40 \pm 0.35 \mathrm{mM}, n=6$ vs.
$2.30 \pm 0.45, n=6, P<0.05)$ and a greater increase in IRI plasma levels, (Figure 11) (similarly, $\Delta$ at $30 \mathrm{~min}$ was: $116.60 \pm 28.10 \%, n=6$ vs. $325.65 \pm 59.05 \%, n=8, P<0.001)$.

Finally, efaroxan alone induced an increase in circulating insulin $(\Delta$ at $30 \mathrm{~min}=196.9 \%$, mean of 2 animals $v s$. $-2.90 \pm 2.85 \%, n=7$, in saline control rabbits) which persisted for $90 \mathrm{~min}$ ( $\Delta$ at $60 \mathrm{~min}=603.65 \pm 260 \%$ ). When administered before glucose it also enhanced insulin secretion $(\Delta$ at $30 \mathrm{~min}=356.35 \pm 60 \%, n=2$ vs. $116.60 \pm 28.10$, $n=6$ in glucose treated animals). However, this insulin secretory effect persisted for as long as $9 \mathrm{~h}$, the animals remaining in hypoglycaemia. Therefore, in vivo experiments with this molecule were discontinued.

Pre-infusion absolute values of arterial plasma glucose and circulating insulin for saline, glucose and drug treated animals ranged between $4.56 \pm 05$ and $6.62 \pm 0.25 \mathrm{mM}$, and $5.65 \pm 1.60$ and $12.15 \pm 2.70 \mu \mathrm{IU} \mathrm{ml}^{-1}$, respectively. 

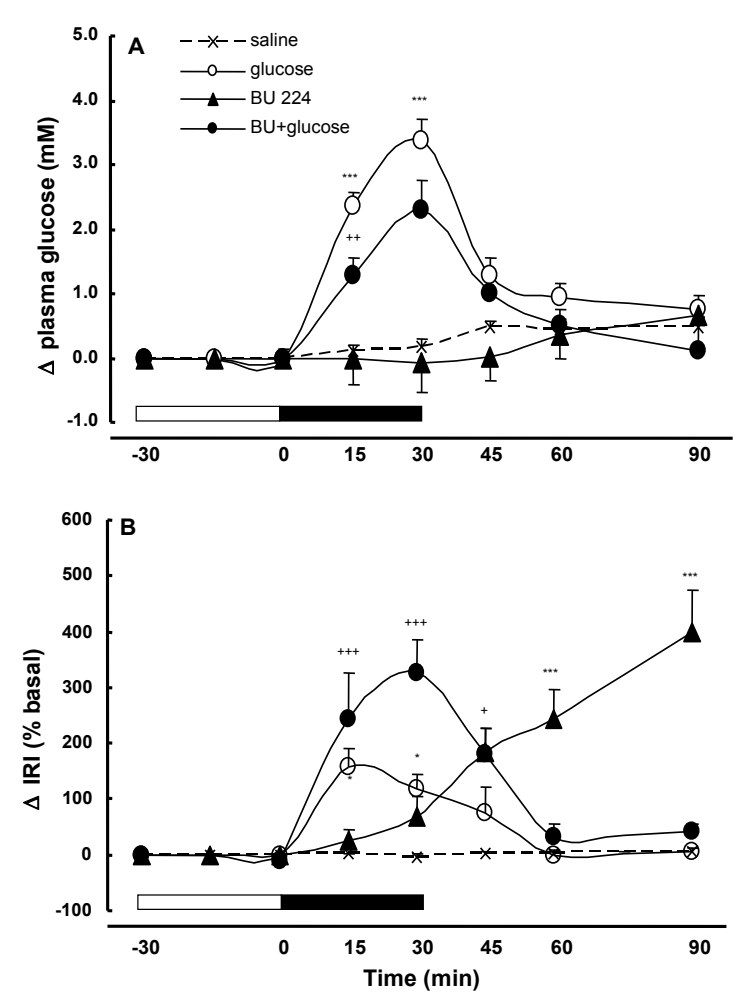

Figure 11. Changes in plasma glucose (A) and in immunoreactive insulin (IRI) (B) levels in conscious fasted rabbits, measured after the i.v. infusion of physiological saline (-X-), glucose alone (-O-, $\left.10 \mathrm{mg} \mathrm{kg}^{-1} \mathrm{~min}^{-1}\right)$, BU $224\left(-\boldsymbol{\Delta}-10 \mu \mathrm{g} \mathrm{kg}^{-1} \mathrm{~min}^{-1}\right)$ and BU 224+glucose (- -); the BU 224 was infused for 30 min (open bar) just before a $30 \mathrm{~min}$ glucose infusion (black horizontal bar). Ordinate scales, $\Delta \mathrm{mM}$ plasma glucose refers to the variations from control values. $\Delta$ IRI levels are expressed as percentage changes from the control level (control=100\%). Each point of any given curve represents the mean \pm s.e.m. for at least 7 rabbits. $* P<0.05$ and $* * * P<0.001$, values significantly different between glucose or BU $224 v s$. saline. $+P<0.05,++P<0.01$, and $+++P<0.001$, values significantly different between glucose $v s$. glucose+BU 224.

\section{DISCUSSIONS}

Studies on insulin secretion have mainly been carried out using mouse and/or rat isolated islets. However, there is a lack of experimental data for other animal species, rabbit included. Since rabbit tissues are very rich in imidazoline binding sites $[17,24]$ this animal was chosen for the present work. The results reported in this study assess the validity of our model: insulin release from isolated islets was glucose-dependent and very sensitive to changes in the extracellular concentrations of $\mathrm{Ca}^{2+}$ and $\mathrm{K}^{+}$ions. Similarly, conventional stimulatory and/or inhibitory responses (i.e., to forskolin, diazoxide) were also confirmed.

Idazoxan induced a very clear dose-dependent insulin secretory response. These are rather paradoxical results, since it has been reported that idazoxan is unable to re- lease insulin in the rat, or it has a weak concentration independent effect in mouse $[13,14]$. An even more $\mathrm{I}_{2}$-selective ligand, BU 224 [27], also evoked a dosedependent secretory response, as did the well known and studied ligand efaroxan [1]. In this model methoxy-idazoxan assayed over a wide range failed to elicit insulin release, thus corroborating its nature as a true $\alpha_{2}$-adrenoceptor antagonist. This property was also shared by idazoxan and it was unmasked when tested against the $\alpha_{2}$-adrenoceptor agonist brimonidine (UK 14,304). In this way, idazoxan reflected its established dual behaviour. However, no interaction with $\alpha_{2}$-adrenoceptors could be found with BU 224 .

The mode of action of imidazolines is complex. Classical insulinotropic compounds inhibit $\mathrm{K}_{\text {ATP }}$ channels in the $\beta$-cell, but, in addition, they exert a direct effect on exocytosis $[7,32]$. The three ligands studied behaved as $\mathrm{K}_{\text {ATP }}$ channel blockers. Interaction of efaroxan with $\mathrm{K}_{\text {ATP }}$ channels could be inferred from perifusion studies and when incubating the islets in the presence of diazoxide, since efaroxan alleviated the suppressive effect on insulin release induced by the potassium channel opener. Similar results have been reported for rat islets [30] using other imidazoline drugs (RX871024, S-22068 [4, 34] and in the present work with the selective $\mathrm{I}_{2}$-ligand BU 224. However, diazoxide abolished the response to idazoxan, but not to BU 224. It is necessary to consider at this time that in mouse islets idazoxan induces a partial inhibition of $\mathrm{K}_{\mathrm{ATP}}$ channels, sufficient to depolarize the plasma membrane and to open voltage-dependent $\mathrm{Ca}^{2+}$ channels with a subsequent modest increase in intracellular calcium [13]. In the presence of partial channel inhibition, diazoxide, by reducing the binding affinity of the ligand, could easily suppress the response. It is also noteworthy that nimodipine similarly abolished the effect of idazoxan and that just simple reduction in the $\mathrm{Ca}^{2+}$ concentration in the extracellular medium severely attenuated the ligand response. An $\alpha-1$ partial agonist effect of idazoxan has been recently reported [35]. However there is no evidence for a $\alpha-1$ adrenoceptor involvement in insulin secretion in isolated islets [36]. When rabbit islets were incubated in the presence of the selective $\alpha-1$ adrenoceptor agonist, amidephrine, no insulin secretory response was found (glucose $8 \mathrm{mM} 11.6 \pm 1.4 \mathrm{vs}$ amidefrine $10.5 \pm 2.2 \mu \mathrm{IU} \mathrm{ml}^{-1}$ islet $\left.^{-1} \mathrm{~h}^{-1}\right)$. In the same experimental situations, BU 224 was still able to increase insulin release.

It is also accepted that this kind of imidazoline compounds block the $\mathrm{K}_{\text {ATP }}$ channel at the level of the Kir6.2 pore [9]. Our experimental results, studying drug interactions among themselves and in the presence of tolbutamide, trend to support this notion. Simultaneous addition of efaroxan and idazoxan, or efaroxan and BU 224, did not lead to synergism or antagonism, probably considering that the three ligands shared a common drug binding site at the pore level [37]. On the other hand, an additive effect was found when BU 224 and tolbutamide were administered together. Indeed, the imidazoline could not displace the 
sulphonylurea from its SUR1 receptor. The ensuing enhanced response could result from additive effects at the $\mathrm{K}_{\text {ATP }}$ channel, or by BU 224 activation of a signaltransduction pathway (see below). Similar results have been reported with other imidazolines [14,38].

It is also well established that insulin secretion in the presence of these compounds exhibited glucose dependency $[8,38]$. Identical results, expressing the requirement for a high energy state of the cell (high ATP/ADP ratio) have been found with the $\mathrm{I}_{2}$-ligands used in this work.

Studies with permeabilised islets and HIT T15 cells have revealed a direct effect of imidazolines (RX871024, BL11282) on exocytosis independent of $\mathrm{K}_{\text {ATP }}$ channel activity. PKA and PKC, with subsequent activation of protein phosphorylation/dephosphorylation steps, would play a central role in the regulation of this process [8]. However, these kinase inhibitors failed to alter the response to efaroxan and idazoxan [12]. Our results, using either PKA/PKC inhibitors or excess $\mathrm{K}^{+}$, confirm that efaroxan and idazoxan induced insulin secretion is dependent of $\mathrm{K}_{\mathrm{ATP}}$ channel activity, whereas the effect of BU 224 requires, in addition, PK activation. A synergism between the effect of BU 224 and either forskolin or IBMX on insulin secretion was also evident, suggesting the permissive role of PKA activity on this particular response.

Interestingly, the compound KU 14R, known as an efaroxan antagonist [39], did not alter, in the present work, the response to this ligand, though it blocked the effect of BU 224, significantly attenuating the response to forskolin [40]. A lack of antagonism between efaroxan and KU 14R has also been reported recently in mouse islets [41]. Consequently an association among BU 224-PKA-KU $14 \mathrm{R}$ could be inferred in our model. It is noteworthy that at the concentrations used in the present work BU 224 behaved as a reversible inhibitor of MAO A and B, preventing hydrogen peroxidase production in adipose tissue [42]. However, in our model MAO inhibition did not modify glucose or BU 224 mediated insulin release. At this point it is interesting to note that the total capacity of the pancreas to oxidise MAO substrates was limited compared with the overall mass and amine oxidase activities of muscular and adipose tissue [43]. Therefore these results reassess the true nature of BU 224 as an $\mathrm{I}_{2}$ ligand, though the response under study seems to be independent of MAO binding sites. It has been reported recently that selective $\mathrm{I}_{2}$-ligands can bind creatine kinase $[44,45]$, a key enzyme important for ATP synthesis. This additional interaction would help to understand the mechanism(s) of BU 224 induced insulin release, considering the importance of ATP for exocytosis even at stages distal to an increase in $\left[\mathrm{Ca}^{+2}\right]_{\mathrm{i}}$ (see experiments at high concentrations of $\mathrm{K}^{+}$).

The presence of $\mathrm{I}_{2}$ binding sites (IBS) mediating the effects of these ligands has not been accepted on the basis of the failure of idazoxan to elicit insulin secretion, lack of data with more selective $\mathrm{I}_{2}$-ligands and binding studies with methoxy-idazoxan. Results presented in this work refute these premises. In addition the ligand BTS 67582 can bind to the $\mathrm{I}_{2}$ imidazoline receptor with potency consistent with its effect on insulin secretion [46]. The drug could regulate insulin release by an interaction with the $\mathrm{K}_{\text {ATP }}$ channel or by exerting a direct effect in the process of exocytosis $[46,47]$. Curiously indeed, idazoxan and BU 224 also increase insulin release, blocking $\mathrm{K}_{\text {ATP }}$ channel activity at a site shared by the third imidazoline ligand efaroxan. Therefore, considering that a number of $\mathrm{I}_{2}$-ligands can bind a common site on the channel, this binding site, independent of MAO activity, might be considered as a variant or subtype of the classic $\mathrm{I}_{2}$-binding site. It is also known that the presence of $\mathrm{I}_{2}$ sites on MAO enzyme can not satisfactorily represent the diverse biological targets of $\mathrm{I}_{2}$-ligands [48,49]. Intracellular binding sites linked to protein kinase(s) activation ( $\mathrm{I}_{3}$-receptor?) would also be involved in the amplifying effect of BU 224.

In vivo studies reassess in vitro data. Idazoxan and $\mathrm{BU}$ 224 , but not yohimbine, enhanced the insulin secretory response to a glucose load. Temporal patterns of insulin secretion when BU 224 was infused alone or in the presence of glucose showed the complex behaviour of this molecule: its glucose dependency as well as its interaction with $\mathrm{K}_{\text {ATP }}$ dependent and independent mechanisms. When comparing circulating levels of insulin after a glucose challenge in animals pretreated with any of the three drugs, idazoxan was able to induce the maximal response. The dual nature of this ligand should be borne in mind: its ability to block: 1) pre and post-synaptic $\alpha_{2}$ adrenoceptors and thus increase plasma catecholamine levels [50], with a subsequent $\beta$-adrenoceptor mediated effect; and 2) $\mathrm{K}_{\mathrm{ATP}}$ channels as an I-ligand (like BU 224). Combined mechanisms would be responsible for such an effect.

Though BU 224 showed a greater antihyperglycaemic effect than idazoxan, the effect was lower than expected considering its ability to release insulin and to restrain lipolysis [42]. However this molecule, being an MAO inhibitor, should prevent metabolic inactivation of endogenous catecholamines, thus enhancing intrinsic sympathomimetic activity. Non-selective blocking of Kir6.2 affecting channels at several locations could also unmask compensatory responses able to attenuate the blood glucose lowering response.

\section{CONCLUSIONS}

The imidazoline ligands interacting with either $\mathrm{I}_{2}$ or $\mathrm{I}_{3}$-binding sites would mediate in vitro, as well as in vivo, insulin secretion. However, additional extrapancreatic sites of action would attenuate their antihyperglycaemic effect. In conclusion, the administration of BU 244 in- 
duces extended insulin release that would produce potential hypoglycaemia. This could be an adverse effect whether this molecule is used as antidiabetic drug.

\section{ACKNOWLEDGEMENTS}

The authors express gratitude to Mr. G.H. Jenkins for his help with the English version of the manuscript. We are very grateful for the financial support from Junta de Castilla y León (JCYL), grant $n^{\circ}$ SA42/00B (Spain).

\section{REFERENCES}

[1] Chan, S.L., Brown, C.A., and Morgan, N.G. (1993) Stimulation of insulin secretion by the imidazoline alpha 2-adrenoceptor antagonist efaroxan is mediated by a novel, stereoselective, binding site. Eur J Pharmacol, 230(3), 375-8.

[2] Schulz, A. and Hasselblatt, A. (1989) An insulin-releasing property of imidazoline derivatives is not limited to compounds that block alpha-adrenoceptors. Naunyn Schmiedebergs Arch Pharmacol, 340, 321-7.

[3] Berdeu, D., Puech, R., Ribes, G., Loubatieres-Mariani, M.M., and Bertrand, G. (1997) Antazoline increases insulin secretion and improves glucose tolerance in rats and dogs. Eur J Pharmacol, 324, 233.

[4] Pele-Tounian, A., Chan, S.L., Rondu, F., Le Bihan, G., Giroix, M.H., Lamouri, A., Touboul, E., Pfeiffer, B., Manechez, D., Renard, P., Guardiola-Lemaitre, B., Godfroid, J.J., Penicaud, L., Morgan N.G., and Ktorza A. (1999) Effect of the new imidazoline derivative S-22068 (PMS 847) on insulin secretion in vitro and glucose turnover in vivo in rats. Eur J Pharmacol, 377, 81-87.

[5] Wang, X., Rondu, F., Lamouri, A., Dokhan, R., Marc, S., Touboul, E., Pfeiffer, B., Manechez D., Renard, P., Guardiola-Lemaitre, B., Godfroid, J.J., Ktorza, A., and Penicaud, L. (1996) Effect of S-21663 (PMS 812), an imidazoline derivative, on glucose tolerance and insulin secretion in a rat model of type II diabetes. $J$ Pharmacol Exp Ther, 278, 82-89.

[6] Williams, C.A., Shih, M.F., and Taberner, P.V. (2000) Effect of acute and sub-chronic administration of the imidazoline compound S22068 on in vivo glucose and insulin responses in normal lean $\mathrm{CBA} / \mathrm{Ca}$ mice. Gen. Pharmacol., 34, 183-91.

[7] Efendic, S., Efanov, A.M., Berggren, P.O., and Zaitsev, S.V. (2002) Two generations of insulinotropic imidazoline compounds. Diabetes, 51 (3), S448-S547.

[8] Efanov, A.M., Zaitsev, S.V., Mest, H.J., Raap, A., Appelskog, I.B., Larsson, O., Berggren, P.O., and Efendic, S. (2001) The novel imidazoline compound BL11282 potentiates glucose-induced insulin secretion in pancreatic beta-cells in the absence of modulation of $\mathrm{K}_{\text {ATP }}$ channel activity. Diabetes, 50, 797-802.

[9] Proks, P. and Ashcroft, F.M. (1997) Phentolamine block of $\mathrm{K}_{\text {ATP }}$ channels is mediated by Kir6.2. Proc Natl Acad Sci USA, 94, 1716-20.

[10] Morgan, N.G., Chan, S.L., Mourtada, M., Monks, L.K., and Ramsden, C.A. (1999) Imidazolines and pancreatic hormone secretion. Ann N Y Acad Sci, 881, 217-28.
[11] Farret, A., Lugo-Garcia, L., Galtier, F., Gross, R., and Petit, P. (2005) Pharmacological interventions that directly stimulate or modulate insulin secretion from pancreatic beta-cell: Implications for the treatment of type 2 diabetes. Fundam Clin Pharmacol, 19, 647-656.

[12] Mourtada, M., Smith, S.A., and Morgan, N.G. (1998) Effector systems involved in the insulin secretory responses to efaroxan and RX871024 in rat islets of Langerhans. Eur J Pharmacol, 350, 251-8.

[13] Rustenbeck, I., Leupolt, L., Kowalewski, R., and Hasselblatt, A. (1999) Heterogeneous characteristics of imidazoline-induced insulin secretion. Naunyn Schmiedebergs Arch Pharmacol, 359, 235-42.

[14] Mourtada, M., Brown, C.A., Smith, S.A., Piercy, V., Chan, S.L., and Morgan, N.G. (1997) Interactions between imidazoline compounds and sulphonylureas in the regulation of insulin secretion. Br J Pharmacol, 121, 799-805.

[15] Berdeu, D., Gross, R., Puech, R., Loubatieres-Mariani, M.M., and Bertrand, G. (1995) Evidence for two different imidazoline sites on pancreatic B cells and vascular bed in rat. Eur J Pharmacol, 275, 91-8.

[16] Zaitsev, S.V., Efanov, A.M., Raap, A., Efanova, I.B., Schloos, J., Steckel-Hamann, B., Larsson, O., Ostenson, C.G., Berggren, P.O., Mest, H.J., and Efendic, S. (1999) Different modes of action of the imidazoline compound RX871024 in pancreatic beta-cells: Blocking of $\mathrm{K}^{+}$ channels, mobilization of $\mathrm{Ca}^{2+}$ from endoplasmic reticulum, and interaction with exocytotic machinery. Ann NY Acad Sci, 881, 241-52.

[17] Boronat, M.A., Olmos, G., Miller, D.D., Patil, P.N., and Garcia-Sevilla, J.A. (1998) Isothiocyanatobenzyl imidazoline is an alkylating agent for $\mathrm{I}_{2}$-imidazoline binding sites in rat and rabbit tissues. Naunyn Schmiedebergs Arch Pharmacol, 357, 351-57.

[18] Chan, S.L., Brown, C.A., Scarpello, K.E., and Morgan, N.G. (1994) The imidazoline site involved in control of insulin secretion: Characteristics that distinguish it from I1- and $\mathrm{I}_{2}$-sites. Br J Pharmacol, 112, 1065-70.

[19] Le Brigand, L., Virsolvy, A., Manechez, D., Godfroid, J.J., Guardiola-Lemaitre, B., Gribble, F.M., Ashcroft, F.M., and Bataille, D. (1999) In vitro mechanism of action on insulin release of S-22068: A new putative antidiabetic compound. Br J Pharmacol, 128, 1021-6.

[20] Cooper, E.J., Hudson, A.L., Parker, C.A., and Morgan, N.G. (2003) Effects of the beta-carbolines, harmane and pinoline: On insulin secretion from isolated human islets of Langerhans. Eur J Pharmacol, 482, 189-96.

[21] Mayer, G. and Taberner, P.V. (2002) Effects of the imidazoline ligands efaroxan and KU14R on blood glucose homeostasis in the mouse. Eur J Pharmacol, 454, 95-102.

[22] Ernsberger, P. (1992) Heterogeneity of imidazoline binding sites: Proposed I1 and I2 subtypes. Fund Clin Pharmacol., 6(1), 55S.

[23] Coupry, I., Podevin, R.A., Dausse, J.P., and Parini, A. (1987) Evidence for imidazoline binding sites in basolateral membranes from rabbit kidney. Biochem Biophys Res Commun, 147, 55-60.

[24] Hudson, A.L, Husbands, S., Lewis, J.W., and Nutt, D.J. (1994) Affinity and selectivity of BU224 and BU239 for rabbit brain non-adrenoceptor idazoxan binding sites ( $\mathrm{I}_{2}$-sites). Br J Pharmacol, 112, (Proceedings Suppl), 320.

[25] Jou, S.B., Liu, I.M., and Cheng, J.T. (2004) Activation of 
imidazoline receptor by agmatine to lower plasma glucose in streptozotocin-induced diabetic rats. Neurosci Lett, 358, 111-4.

[26] MacInnes, N. and Handley, S.L. (2002) Characterization of the discriminable stimulus produced by 2-BFI: Effects of imidazoline I(2)-site ligands, MAOIs, beta-carbolines, agmatine, and ibogaine. Br J Pharmacol, 135, 1227-34.

[27] Nutt, D.J., French, N., Handley, S., Hudson, A., Husbands, S., Jackson, H., Jordan, S., Lalies, M.D., Lewis, J., Lione, L., et al. (1995) Functional studies of specific imidazoline-2 receptor ligands. Ann N Y Acad Sci, 763, 125-39.

[28] García-Barrado, M.J., Sancho, C., Iglesias-Osma, M.C., and Moratinos, J. (2001) Effects of verapamil and elgodipine on isoprenaline-induced metabolic responses in rabbits. Eur J Pharmacol., 415, 105-115.

[29] Moratinos, J., Carpene, C., De Pablos, I., and Reverte, M. (1988) Role of alpha 1- and alpha 2-adrenoceptors in catecholamine-induced hyperglycaemia, lipolysis and insulin secretion in conscious fasted rabbits. $\mathrm{Br} J$ Pharmacol, 94, 299-310.

[30] Chan, S.L., Dunne, M.J., Stillings M.R., and Morgan, N.G. (1991) The alpha 2-adrenoceptor antagonist efaroxan modulates $\mathrm{K}^{+}{ }_{\text {ATP }}$ channels in insulin-secreting cells. Eur $J$ Pharmacol, 204, 41-8.

[31] Gembal, M., Gilon, P., and Henquin, J.C. (1992) Evidence that glucose can control insulin release independently from its action on ATP-sensitive $\mathrm{K}^{+}$channels in mouse B cells. J Clin Invest, 89, 1288-95.

[32] Cuchillo-Ibanez, I., Lejen, T., Albillos, A., Rose, S.D., Olivares, R., Villarroya, M., et al. (2004) Mitochondrial calcium sequestration and protein kinase $\mathrm{C}$ cooperate in the regulation of cortical F-actin disassembly and secretion in bovine chromaffin cells. $J$ Physiol, 560, 63-76.

[33] Henquin, J.C. (2004) Pathways in beta-cell stimulussecretion coupling as targets for therapeutic insulin secretagogues. Diabetes, 53 (3), S48-S58.

[34] Zaitsev, S.V., Efanov, A.M., Efanova, I.B., Larsson, O., Ostenson, C.G., Gold, G., Berggren, P.O., and Efendic, S. (1996) Imidazoline compounds stimulate insulin release by inhibition of $\mathrm{K}_{\text {ATP }}$ channels and interaction with the exocytotic machinery. Diabetes, 45, 1610-1618.

[35] Serban, D.N., Serban, I.L., and Nechifor, M. (2004) Idazoxan effects upon contractile activity in the rat aorta are related to alpha adrenoceptors and L-type channels. Fundan Clin Pharmacol, 18, 635-41.

[36] Malaisse, W.J. and Moratinos, J. (1986) Are pancreatic beta-cells equipped with alpha-1 adrenoceptors? IRCS Med Sci, 1194-1195.

[37] Ugedo, L., Pineda, J., Ruiz-Ortega, J.A., and Martin-Ruiz, R. (1998) Stimulation of locus coeruleus neurons by non-I1/I2-type imidazoline receptors: An in vivo and in vitro electrophysiological study. Br J Pharmacol, 125, 1685-1694.

[38] Efanov, A.M., Zaitsev, S.V., Efanova, I.B., Zhu, S., Ostenson, C.G., Berggren, .PO., and Efendic, S. (1998) Signalling and sites of interaction for RX-871024 and sulfonylurea in the stimulation of insulin release. $\mathrm{Am} \mathrm{J}$
Physiol, 274, E751-E757.

[39] Mourtada, M., Chan, S.L., Smith, S.A., and Morgan, N.G. (1999) Multiple effector pathways regulate the insulin secretory response to the imidazoline RX871024 in isolated rat pancreatic islets. Br J Pharmacol, 127, 12791287.

[40] Chan, S.L., Mourtada, M., and Morgan, N.G. (2001) Characterization of a $\mathrm{K}_{\mathrm{ATP}}$ channel-independent pathway involved in potentiation of insulin secretion by efaroxan. Diabetes, 50, 340-347.

[41] Bleck, C., Wienbergen, A., and Rustenbeck, I. (2005) Essential role of the imidazoline moiety in the insulinotropic effect but not the $\mathrm{K}_{\text {ATP }}$ channel-blocking effect of imidazolines: A comparison of the effects of efaroxan and its imidazole analogue, KU14R. Diabetologia, 48, 2567-75.

[42] Bour, S., Iglesias-Osma, M.C., Marti, L., Duro, P., Garcia-Barrado, M.J., Pastor, M.F., Prevot, D., Visentin, V., Valet, P., Moratinos, J., and Carpene, C. (2006) The imidazoline $\mathrm{I}_{2}$-site ligands BU 224 and 2-BFI inhibit MAO-A and MAO-B activities, hydrogen peroxide production, and lipolysis in rodent and human adipocytes. Eur $J$ Pharmacol, 552, 20-30.

[43] Iglesias-Osma, M.C., Garcia-Barrado, M.J., Visentin, V., Pastor-Mansilla, M.F., Bour, S., Prevot, D., Valet, P., Moratinos, J., and Carpene, C. (2004) Benzylamine exhibits insulin-like effects on glucose disposal, glucose transport, and fat cell lipolysis in rabbits and diabetic mice. J Pharmacol Exp Ther, 309, 1020-1028.

[44] Kimura, A., Tyacke, R.J., Minchin, M.C., Nutt, D.J., and Hudson, A.L. (2003) Identification of an I(2) binding protein from rabbit brain. Ann NY Acad Sci, 1009, 364-366.

[45] Paterson, L.M., Robinson, E.S., Nutt, D.J., and Hudson, A.L. (2003) In vivo estimation of imidazoline(2) binding site turnover. Ann N Y Acad Sci, 1009, 367-370.

[46] Dickinson, K., North, T.J., and Jones, R.B. (1999) BTS 67 582 may mediate insulin secretion via the putative pancreatic islet imidazoline receptor. Br J Pharmacol, 126, 133.

[47] Page, T.B.C.J. (1997) Glucose-lowering effect of BTS 67 582. Br J Pharmacol, 122, 1464-8.

[48] Tesson, F., Limon-Boulez, I., Urban, P., Puype, M., Vandekerckhove, J., Coupry, I., Pompon, D., and Parini, A. (1995) Localization of $\mathrm{I}_{2}$-imidazoline binding sites on monoamine oxidases. J Biol Chem, 270, 9856-61.

[49] Marti, L., Morin, N., Enrique-Tarancon, G., Prevot, D., Lafontan, M., Testar, X., Zorzano, A., and Carpene, C. (1998) Tyramine and vanadate synergistically stimulate glucose transport in rat adipocytes by amine oxidasedependent generation of hydrogen peroxide. J Pharmacol Exp Ther, 285, 342-9.

[50] Portillo, M., Reverte, M., Langin, D., Senard, J.M., Tran, M.A., Berlan, M., and Montastruc, J.L. (1991) Effect of a 7-day treatment with idazoxan and its 2-methoxy derivative RX 821002 [correction of RX 821001] on alpha 2-adrenoceptors and non-adrenoceptor idazoxan binding sites in rabbits. Br J Pharmacol, 104, 190-194. 